\title{
A MÍDIA A SERVIÇO DA RELIGIÃO: O ENTRELAÇAMENTO DE VOZES NO DISCURSO DA RENOVAÇÃO CARISMÁTICA CATÓLICA
}

\author{
Evandra Grigoletto
}

RESUMO: Le présent article examine, à partir de la théorie de l'École Française de l'Analyse du Discours, comme le média fonctionne au service de la réligion dans le discours de la Rénovation Charismatique Catholique. Pour observer tel fonctionnement, j'analyse quelques séquences discursives de lettres de lecteurs et éditoraux de la Revue Brasil Cristão. Questions comme: Il y a des voix différentes réprensentées dans l'éditorial et dans les lettres? Quelles? Telles voix occupent différentes positions de sujet? Quel est le lieu de la voix du croyant? Et du prêtre qui signe l'éditorial? Comment le média fonctionne dans ce procès? Et quel est-il le rôle du discours journalistique? Pour répondre à de telles questions, je mobilise les concepts de forme empirique et de forme matérielle, aussi bien que ceux de mémoire et hétérogénéité discursives.

PALAVRAS-CHAVE: discurso, religião, mídia, apropriação, heterogeneidade, sobredeterminação, efeitos de sentido.

\section{CONSIDERAÇÕES INICIAIS}

Inicio este artigo fazendo referência à designação que escolhi para

Evandra Grigoletto é doutoranda em Teorias do Texto e do Discurso na UFRGS. 
intitulá-lo: "A mídia a serviço da religião". Talvez, num primeiro momento, ela pode causar um certo incômodo. Afinal, não é, ou pelo menos, não era muito comum associar a religião à mídia, já que os objetivos de uma e de outra são diversos. À religião cabe a tarefa de evangelizar, doutrinar os seus fiéis, enquanto à mídia cabe o papel de informar, entreter seus telespectadores ${ }^{1}$. Como, então, a mídia coloca-se a serviço da religião? Refletir sobre tal questionamento é o desafio deste trabalho.

$\mathrm{E}$, para entender como funciona tal associação, é preciso buscar as condições de produção que constituem o discurso da Renovação Carismática Católica, situando-o histórica e socialmente. A chegada do ano 2000 marcou, entre outras coisas, o aniversário de dois mil anos de Jesus Cristo. E tal fato foi muito lembrado e divulgado, principalmente pela Igreja Católica. Todos sabemos que desde o nascimento de Jesus Cristo até os dias de hoje muita coisa mudou, principalmente, no que se refere à tecnologia. Surgiram o rádio e a televisão, os jornais e as revistas e agora estamos vivendo a era da internet que, a cada dia, está evoluindo mais. Assim, a Igreja Católica que, no decorrer desses dois séculos, já deteve muito poder em suas mãos e, por outro lado, já perdeu muito prestígio e conseqüentemente muito desse poder, entra o novo milênio na era da tecnologia com a intenção de resgatar o prestígio perdido.

Com a expansão das outras Igrejas que começam a surgir e com a perda dos fiéis, surge, dentro da Igreja Católica, o movimento da Renovação Carismática, cuja preocupação está voltada para a conquista de novos fiéis através dos mais modernos meios de comunicação: rádio, televisão, revistas, CDs, e-mail, etc. A religião está inserida, então, na "guerra" dos meios de comunicação pela conquista de um espaço na sociedade, utilizando-se do serviço da mídia para evangelizar. Para tanto, apropria-se do discurso jornalístico, que até então era quase exclusividade dos jornais diários e revistas semanais.

O movimento da Renovação Carismática Católica (RCC doravante) surgiu nos Estados Unidos em 1967 e difundiu-se pelo mundo. Reunidos em retiro, cerca de trinta leigos católicos, insatisfeitos com seu estilo de vida, preocupações acadêmicas e experiências religiosas, buscavam uma forma de renovação espiritual. Enquanto rezavam, teria ocorrido o que chamaram Pentecostes renovado. A partir daí, estavam lançadas as bases do que viria a ser a Renovação Carismática, um movimento pentecostal que se inscreve na linha da Nova Evangelização da Igreja, apregoada por João Paulo II, e que visa reter os seus fiéis e barrar o avanço

\footnotetext{
${ }^{1}$ Há que se destacar, no entanto, que tal papel da mídia não é neutro. Pelo contrário, muitas vezes as informações são manipuladas de modo a atender os interesses da emissora e não dos telespectadores.
} 
pentecostal. E, para cumprir tal objetivo, a Renovação Carismática passa a empregar as mesmas estratégias que as igrejas Pentecostais, entre elas, a utilização dos ‘serviços’ da mídia.

Situadas, ainda que brevemente, as condições de produção nas quais está inserido o movimento da Renovação Carismática Católica, percebemos que tal movimento é constituído histórica e socialmente no passado e no presente. Num presente em que vivemos o início de um novo milênio numa sociedade globalizada e num passado que, há dois mil anos, marcou o nascimento de Jesus Cristo, o qual foi e continua sendo motivo de comemoração para a Igreja Católica.

Então, ainda perseguindo a reflexão sobre a designação que intitula o meu trabalho "A mídia a serviço da religião" e já avançando para a discussão do subtítulo "o entrelaçamento de vozes no discurso da Renovação Carismática Católica”, passo a apresentar o corpus selecionado para o presente trabalho, seguido das análises, que estão ancoradas na teoria da Escola Francesa de Análise do Discurso, preconizada por Michel Pêcheux.

Para observar o funcionamento das diferentes vozes ${ }^{2}$ que se entrelaçam no discurso da Renovação Carismática, vou analisar os Editoriais dos meses de abril e maio de 2000 da Revista Brasil Cristão, bem como algumas cartas de leitores das mesmas edições. Cabe ainda salientar que tal revista é um dos veículos de comunicação oficial do movimento carismático, servindo de canal entre a Associação do Senhor Jesus e seus sócios, fiéis contribuintes. Cada sócio de Jesus, designação dada aos fiéis pelos padres carismáticos, deve contribuir mensalmente com uma quantidade mínima estipulada para receber em sua casa a Revista Brasil Cristão, que é exclusiva dos sócios. Para melhor elucidar o que estou dizendo, apresento uma mensagem do Padre Eduardo Dougherty, presidente da Associação do Senhor Jesus, que aparece na primeira página da revista do mês de Abril de 2000, juntamente com as fichas para novos sócios:

"Muito obrigado por tudo, sócio amigo de Jesus" !

Obrigado por fazer do seu objetivo o nosso objetivo em comum: evangelizar o Brasil e o mundo através da televisão. Eu só posso dizer a você: Deus abençoe você e lhe retribua o cêntuplo. Muito obrigado, mesmo!

Continuamos caminhando na fé e na confiança! Conto com a sua ajuda. Por favor, envie-me mais sócios de coração fiel e generoso como seu. Ajude-me a construir um mundo melhor!" (BRASIL CRISTÃO, abril/2000)

Aqui, nesse agradecimento e também pedido de ajuda, observamos

\footnotetext{
${ }^{2}$ Leia-se aqui a voz do Padre, de Deus, dos fiéis, da instituição ASJ (Associação do Senhor Jesus) e da mídia.

${ }^{3}$ Os grifos são meus.
} 
a presença tanto da voz do padre como da voz dos fiéis, ou melhor, sócio amigo de Jesus!. No entanto, essa heterogeneidade de vozes aponta para um único objetivo: evangelizar o Brasil e o mundo através da televisão. Eis a presença da mídia, ou melhor, o serviço da televisão à disposição da evangelização. Portanto, a voz do fiel aí representada por marcas como 'seu objetivo, você, sua ajuda' ocupa uma posição de dominada, de submissão em relação à voz do padre. Trata-se de uma voz que é sobredeterminada, saturada pelos saberes divinos. Veja que o novo sócio deve ter o coração fiel e generoso. Fiel para continuar sempre contribuindo com o Senhor Jesus, com a associação que é dELE, cumprindo o que prometeu. E generoso com a contribuição, que sente prazer em doar. Assim, Jesus é transformado em mercadoria e o fiel em sócio-contribuinte. Eis o novo efeito de sentido que emerge do discurso da Renovação Carismática Católica. Efeito este construído com o auxílio da mídia, aqui nesse caso representada pela Revista Brasil Cristão.

Antes de passar às análises dos editoriais e das cartas e testemunhos de leitores, gostaria de apresentar uma reflexão sobre o papel e o funcionamento do discurso jornalístico no discurso religioso, bem como discutir alguns conceitos da teoria discursiva, que serão mobilizados durante as análises.

\section{A CONSTRUÇÃO TEÓRICA}

Ao tomarmos o discurso jornalístico como uma modalidade de discurso sobre (Cf. MARIANI, 1998), podemos dizer que estamos diante, no caso da Revista Brasil Cristão, de um discurso jornalístico sobre religião, em que o objeto, o fato é a evangelização. Ou ainda, olhando por outro viés, podemos dizer que se trata de um discurso religioso que se apropria da forma empírica e de algumas propriedades do funcionamento do discurso jornalístico para atingir seu objetivo maior: evangelizar. Mariani (1998), ao trabalhar com o discurso jornalístico, afirma que

"Os discursos sobre são discursos que atuam na institucionalização dos sentidos, portanto, no efeito de linearidade e homogeneidade da memória. Os discursos sobre são discursos intermediários, pois ao falarem sobre um discurso de ('discurso-origem'), situam-se entre este e o interlocutor, qualquer que seja. De um modo geral, representam lugares de autoridade em que se efetua algum tipo de transmissão de conhecimento, já que o falar sobre transita na correlação entre o narrar/descrever um acontecimento singular, estabelecendo sua relação com um campo de saberes já reconhecido pelo interlocutor" (MARIANI, 1998, p. 60) 
Seja ele religioso ou jornalístico, o objeto de estudo do presente trabalho, é uma modalidade de discurso sobre, já que o próprio discurso religioso proferido pelo padre aos fiéis, ainda que não veiculado por um meio de comunicação (como é o caso aqui), é um discurso sobre Deus, sobre a fé, sobre os dogmas religiosos, etc. Conforme nos diz Orlandi (1990) não é de qualquer lugar que pode se falar sobre. Mas, no discurso religioso, o padre está autorizado, legitimado não só a falar sobre Deus, mas também a fazer falar a voz de Deus, ocupando um lugar de autoridade social, representado pela Igreja ou, nesse caso, pela Associação do Senhor Jesus. E isso corrobora para que haja uma cristalização dos sentidos. Em trabalho anterior (GRIGOLETTO, 2000), afirmo que,

"no discurso religioso, o homem - que pode ser o padre ou não - faz falar a voz de Deus. Não se trata da mesma voz: a voz do padre não é necessariamente a voz de Deus. Entre a voz de Deus, que pertence ao plano divino, e a voz do homem, que pertence ao plano temporal, há um espaço que é preenchido pelo silêncio e pelas relações imaginárias e simbólicas. E é nesse espaço que também se constróem os sentidos do discurso religioso". (GRIGOLETTO, 2000, p. 45)

Eis mais uma justificativa de que estamos trabalhando com uma modalidade de discurso sobre, já que a voz de Deus se faz ouvir através de um interlocutor, seja ele o Padre ou um fiel. Tal interlocutor aciona, via memória discursiva, as relações imaginárias e simbólicas sobre a tradição católica, construídas histórica e socialmente, ocupando um lugar intermediário entre a voz de Deus e a voz do homem.

Juntamente com a memória discursiva, a qual concerne à existência histórica do enunciado no seio de práticas discursivas regradas pelos aparelhos ideológicos ${ }^{4}$ (Cf. COURTINE, 1981), no discurso religioso, podemos mobilizar o conceito de memória coletiva, ${ }^{5}$ enquanto elemento constitutivo de um determinado grupo social. Tal grupo passa, através da história - de geração em geração os seus dogmas, as suas crenças, os seus ensinamentos. Pensemos nos ensinamentos pregados por Jesus Cristo, os quais perduram ao longo de dois mil anos. Eis a memória coletiva que, nesse caso, faz emergir do passado lembranças e ensinamentos que estão

\footnotetext{
${ }^{4} \mathrm{O}$ aparelho ideológico, nesse caso, é a Igreja.

${ }^{5}$ Refiro-me aqui ao conceito de memória coletiva, desenvolvido por Jean Davallon (1999) em um artigo publicado no livro Papel da Memória. Para ele "lembrar um acontecimento ou um saber não é forçosamente mobilizar e fazer jogar uma memória social. Há necessidade de que o acontecimento lembrado reencontre sua vivacidade; e sobretudo, é preciso que ele seja reconstruído a partir de dados e de noções comuns aos diferentes membros da comunidade social". Assim, o enunciado resgatado/lembrado pela memória discursiva só faz sentido porque é (re)atualizado/(re)inscrito numa determinada sociedade, historicamente constituída.
} 
vivos e fazem impressão na vida de muitas pessoas da comunidade católica. Portanto, conserva o passado e permanece, ao mesmo tempo, viva na (in)consciência do grupo.

Segundo Mariani (1998), "a 'objetividade' dos fatos, i.e., sua evidência de visibilidade, resulta inevitavelmente de um gesto interpretativo que se dá a partir de um imaginário já constituído. Sendo assim, ao relatar os acontecimentos, os jornais já estão exercendo uma determinação nos sentidos" (MARIANI, 1998, p. 63). Aqui, a autora está tratando do discurso jornalístico propriamente dito, mas, se reportarmos tal reflexão para o discurso da Revista Brasil Cristão, podemos observar interfaces em comum. Os fatos são os dogmas, os quais são tomados como verdades inquestionáveis, portanto, objetivas, constituídas a partir de um imaginário social da religião. A Revista Brasil Cristão, então, apropria-se da forma empírica do discurso jornalístico, para não só relatar os acontecimentos/ eventos religiosos da Associação do Senhor Jesus mas também para evangelizar. E a evangelização é concretizada, sobretudo, anunciando Jesus, que se transforma em mercadoria graças ao serviços da mídia. Mas para observarmos tais efeitos de sentido, é preciso considerar a forma material (linguístico-histórica) e a ordem do discurso, que vão apresentar funcionamentos diferentes no discurso jornalístico e religioso.

A organização e ordem da língua, assim como a forma empírica e a forma material são noções distintas quando se trata de uma perspectiva discursiva que considera a relação da língua com a história, a qual constitui o discurso. A Análise de Discurso preocupa-se com um ponto de vista materialista, o qual considera a história como constitutiva da língua e, conseqüentemente, do discurso. Não se pode pensar numa separação estanque entre forma (a organização, o empírico) e conteúdo, mas sim, conforme o que nos aponta Orlandi (1996), trabalhar com a noção de forma material que se distingue da forma abstrata (empírica) e considerar, ao mesmo tempo, forma e conteúdo enquanto materialidade. Assim, o analista de discurso passa da organização, da forma empírica, onde estão as marcas, as pistas lingüísticas que lhe possibilitarão fazer a passagem à forma material, à ordem do discurso, que é donde depreendem-se os efeitos de sentido de um discurso. Portanto, a forma empírica produz efeitos de evidências sobre as práticas discursivas.

Por último, antes de passar às análises propriamente ditas, apresento uma breve discussão sobre o conceito de heterogeneidade, o qual estará marcado fortemente na prática analítica.

Atualmente, falar em Análise do Discurso pressupõe falar em heterogeneidade, já que o discurso, enquanto objeto histórico e ideológico dessa teoria, é constitutivamente heterogêneo. Tanto a noção de discurso 
quanto as noções de sujeito e de formação discursiva foram avançando ao longo das formulações teóricas, passando a contemplar o heterogêneo como um elemento intrínseco à sua constituição.

Conforme Indursky (1997) "um discurso é heterogêneo porque sempre comporta constitutivamente em seu interior outros discursos "( INDURSKY, 1997, p.196). É heterogêneo também porque comporta em seu interior contradições, diferentes posições-sujeito. Assim, o efeito de unidade, de homogeneidade do discurso é um espetáculo, uma simulação, que está baseada nas evidências de que o sujeito é a origem do dizer e de que o sentido é literal, transparente.

Falar de heterogeneidade significa, antes de tudo, questionar a unicidade de todo o dizer, considerando a presença do outro na constituição de todo e qualquer discurso, o que significa postular a ideologia e as relações de poder como constitutivas das relações sociais. Negar tais manifestações é camuflar, mascarar a presença da heterogeneidade. Por fim, falar de heterogeneidade significa também considerar os sentidos como múltiplos e o sujeito como cindido, disperso.

Apresentadas, ainda que brevemente, as noções teóricas que serão mobilizadas na prática analítica, passemos às análises propriamente ditas.

\section{AS ANÁLISES}

A escolha do objeto de análise, os editoriais e as cartas de leitores, já garante a presença da heterogeneidade nesse discurso. Afinal, numa revista, seja ela a Brasil Cristão ou uma revista de economia, o editorial e a sessão intitulada "carta dos leitores" são espaços de interlocução com o leitor. Embora nem sempre a reversibilidade (troca de papéis entre interlocutores) aconteça, a voz do leitor está presente. Eis a forma empírica do discurso jornalístico.

O discurso da RCC apropria-se, então, da forma empírica do discurso jornalístico para melhor administrar o(s) sentido(s) que deslizam deste lugar - a Revista Brasil Cristão. Logo, a forma empírica do discurso jornalístico e do religioso são semelhantes, mas o modo como ela significa é diferente.

Se olharmos para a forma empírica, com exceção das ilustrações, as quais não aparecem na transição do anexo, o editorial do mês de abril de 2000 da Revista Brasil Cristão (ver anexo 1) é semelhante ao de uma outra revista qualquer. Mas, ao lançarmos um olhar sobre a forma material, considerando o modo de funcionamento desse texto, os sentidos começam a deslizar. Vejamos. Em primeiro lugar, há que se observar que o leitor a 
quem se dirige o padre não é um leitor qualquer, mas sim um fiel em potencial, um sócio-contribuinte. $\mathrm{O}$ pe. funciona aqui como um intermediário entre a voz de Deus 'Não está aqui, mas ressuscitou...' e a voz do fiel. Então, entre a voz de Deus, que pertence ao plano divino e é representada pelo padre, e a voz do fiel, que pertence ao plano temporal, há um espaço que é preenchido pelo silêncio (...) e pelas relações simbólicas e imaginárias. E é nesse espaço que os sentidos começam a deslizar. Há uma sobredeterminação do plano divino sobre o temporal, já que a notícia de que ele vive dá novo sentido à nossa vida (do padre e dos fiéis). Os saberes/ensinamentos divinos são superiores aos dos fiéis, que precisam deles para as suas vidas terem sentido e estarem com o coração transbordando de alegria e paz. Assim, o espaço aqui destinado à voz do fiel é um espaço de submissão à ordem divina, representada pelo padre, que assume a posição de dominador, enquanto ao fiel lhe é delegada a posição de dominado. Trata-se da ilusão de reversibilidade, a qual é confirmada nos parágrafos seguintes, onde o pe. se dirige aos leitores como sócio de Jesus para desejar-lhes Feliz Páscoa e agradecer a ajuda recebida. Uma ajuda que não é para ele - Padre -, mas para o Senhor Jesus. Então, ao fiel é reforçada a idéia de que ele precisa de Jesus, o qual lhe é anunciado através da Associação do Senhor Jesus, com o auxílio da mídia. Portanto, a voz do divino é sobredeteminante a do fiel, a qual só é incluída ao dizer do padre para reforçar a dominação do divino.

No editorial do mês de abril de 2000 (ver anexo 2), temos, novamente, o entrelaçamento de diferentes vozes: a voz do padre, a voz do fiel, ainda que na posição de dominado, e a voz divina, que é sobredeterminante. A presença do divino é marcada pela citação de parte da oração da AveMaria no início e no final do editorial. Os enunciados presentes nessa citação são repetidos ao longo da existência do Cristianismo, sendo constitutivos da memória coletiva dos católicos. Aqui, eles ressurgem, via memória discursiva, inscrevendo-se de forma própria no discurso da Revista Brasil Cristão, o que aponta para um determinado efeito de sentido. Qual seja: o plano divino, representado por Maria, é soberano em relação ao plano humano, temporal. Assim, ao lado de Jesus, Maria também é transformada em mercadoria, ofertada e anunciada graças ao serviços da mídia.

O padre, tanto nesse como no editorial do mês anterior, identifica-se plenamente com os dizeres da ordem do divino, ocupando uma posição-sujeito dominadora, que, com o auxílio da mídia, tenta controlar os efeitos de sentido para que eles apontem para uma mesma direção. Qual seja: a salvação está em Jesus, em Maria, com quem temos muito a aprender, como por exemplo, ter espírito evangelizador. Afinal, são eles que nos indicam o Caminho, a Verdade e a Vida. É no plano temporal que o indiví- 
duo convive com o circunstancial, com a realidade. E, por conviver com a realidade, convive com os problemas e as dificuldades, as quais são resolvidas ao se passar para o plano divino, pois para Deus não há dificuldade, não há o impossível. Observamos que o padre até cita as mães que pertencem ao plano temporal, mas dá ênfase à Maria, uma Santa Mãe, que intercede dia e noite por todos e cada um em especial, o que nos aponta para a soberania do divino. O padre, então, como representante legítimo de Deus, se investe do poder divino que deve ser considerado absoluto e inquestionável, ultrapassando todos os limites. Por isso, julga-se completo e superior diante dos fiéis, que são os sujeitos pecadores, submetidos à ordem divina. $\mathrm{O}$ fiel é uma espécie de telespectador passivo, que assiste e aplaude o espetáculo que lhe é imposto.

O discurso da Renovação Carismática, então, apropria-se da forma empírica do discurso jornalístico para evangelizar através da mídia. Tal forma empírica, no entanto, ao ser submetida a um olhar discursivo, tornase forma material e, observado o seu funcionamento, aponta para os efeitos de sentido já mencionados e dominantes nesse discurso. Embora percebamos a presença, o entrelaçamento de diferentes vozes, as quais atestam a heterogeneidade do discurso da Renovação Carismática, há uma cristalização dos sentidos que apontam para um mesmo efeito - a soberania do plano divino em relação ao temporal.

Passo agora às análises das cartas de leitores e testemunhos (ver anexos 3 e 4), onde não mais o Pe. é o locutor, mas sim os leitores. Logo, a voz do fiel não é mais incluída ao dizer do padre como nos editoriais, mas é a própria voz do fiel que marca presença no discurso.

No anexo 3, apresento duas cartas publicadas na Brasil Cristão do mês de abril. A primeira delas relata um testemunho de uma graça recebida e inicia-se com um dizer que circula nos ensinamentos da Igreja Católica, um enunciado da ordem do divino, sempre já-lá inscrito na memória dos católicos que emerge, via interdiscurso, na carta dessa fiel. E isso já nos aponta para a sobredeterminação do plano divino. Em seguida, a fiel começa o relato do seu testemunho, confessando-se envergonhada por não acreditar na palavra de Deus “Pedi e recebereis". E continua contando o quanto pedia e rezava a Jesus e a Maria. Até seus sentimentos, seu estado físico e psicológico ela entrega à avaliação de Deus "só Deus sabe”. A voz da fiel aqui é "abafada" pela voz de Deus e pelos ensinamentos divinos. Assim, a palavra de Deus ocupa uma posição de superioridade em relação às palavras inscritas na ordem do plano temporal.

Ainda é interessante observar que a solução do problema relatado pela fiel na carta veio através da Revista Brasil Cristão, que trazia em uma de suas capas a palavra 'Esperança'. Palavras estas grifadas pelos editores da 
revista. Embora em nenhum momento da carta a fiel fale em milagre, podemos, a partir de uma leitura discursiva, observar sim emergir tal efeito de sentido. Afinal, a doença tinha desaparecido com a Graça de Deus. A esperança chegou-lhe através da Brasil Cristão, trazendo liberdade e conforto.

Temos, claramente, nessa carta, um gesto de interpretação dos editores da Revista. Só a escolha para publicar essa e não outra carta já é um forte indicativo disso. Isso sem mencionar os destaques, grifos produzidos pela revista. E eu diria mais... além de um gesto de interpretação, apresenta-se aqui um modo de administrar os sentidos para que os efeitos não sejam diferentes dos pretendidos pela Renovação Carismática Católica e pela Associação do Senhor Jesus. Quais sejam: a ordem do plano divino é sempre superior à do plano temporal, portanto, sobredeterminante. O fiel só acede ao divino através da Associação, da Revista Brasil Cristão. Silenciam-se, assim, palavras que produziriam efeitos de sentido negativos em relação à Revista. A voz do fiel, por sua vez, embora presente, ocupa uma posição de submissão, dominada pela posição da revista, dos padres e membros da Associação do Senhor Jesus. Há, então, somente a ilusão da reversibilidade, da troca de papéis entre os interlocutores de tal discurso.

Na segunda carta que selecionei para análise, assim como na anterior, logo no início, já há a presença da voz divina, dos ensinamentos divinos, os quais emergem, via memória discursiva, para reforçar a posição sobredeterminante do plano divino. Nos parágrafos seguintes, mais uma vez são enfatizadas as qualidades da Revista Brasil Cristão, o que demonstra que a voz do fiel está plenamente identificada com a voz da revista, da Associação do Senhor Jesus. E tal identificação é intensificada quando o fiel afirma que ser sócio desta obra de Deus é realmente um privilégio. Aqui, nesse enunciado, temos Deus sendo apresentado como justificativa para a existência da Associação, que é apresentada como salvação para os fiéis, que ocupam a posição de sócio submisso. Deus transforma-se em dono de empresa e o fiel em seu sócio, graças ao atravessamento da mídia nesse discurso.

$\mathrm{Na}$ carta que selecionei do mês de maio de 2000 (ver anexo 4),o fiel inicia a carta, agradecendo as muitas graças do Senhor Jesus, desde que se tornou sócio. Percebemos aqui, mais uma vez, o plano divino funcionando como sobredeterminante em relação ao temporal, operando 'milagres', salvando vidas dos humanos pecadores.

Tal sentido é reafirmado no parágrafo seguinte, onde o fiel declara que o que não é de Deus, aqui representado pela Brasil Cristão e pela Associação do Senhor Jesus, não é bom, já que só em Deus está a salvação. Então, as coisas, as músicas que circulam no plano temporal e que não têm a 
intervenção do divino são malignas, são um desastre. Silenciam-se assim sentidos indesejáveis, que não exaltem a obra do Senhor Jesus e a Renovação Carismática, os quais não podem e não devem ser ditos no âmbito de uma formação discursiva Católica. Eis um modo de administrar os sentidos.

A seguir, o fiel, ao enunciar que sua vida mudou completamente depois de ter se tornado sócio, reafirma a sua posição de fiel submisso, dominado, entregando o rumo de sua vida nas mãos do Senhor, ou melhor, da Associação, que é dELE. Então, o fiel diz o que a Associação do Senhor Jesus e a Renovação Carismática Católica querem que os outros fiéis escutem. Portanto, a voz do fiel é manipulada de forma que não produza efeitos de sentidos indesejáveis. A Associação do Senhor Jesus, enquanto representante legítima do movimento carismático, controla e tenta administrar os sentidos que circulam e se inscrevem no domínio da Revista Brasil Cristão. Mais uma vez, dizendo o que a Associação deseja que o fiel diga, nesse mesmo parágrafo, a pessoa que assina essa carta afirma que quem canta reza duas vezes, justificando as músicas, que funcionam como práticas evangelizadoras da Renovação Carismática. Logo, a voz do fiel está em perfeita sintonia, plenamente identificada com o dizer carismático. E, ao contrário do que possa parecer, existe apenas a ilusão de reversibilidade, já que o fiel continua ocupando a posição-sujeito de dominado, enquanto os padres ocupam a posição de dominador, sob o pretexto de estar evangelizando o mundo, tornando o Brasil Cristão. Tal posição do padre, no entanto, é autorizada pelo imaginário social que vê na figura do padre um representante de Deus, que incorpora a voz do divino, isto é, que faz falar a voz de Deus.

Portanto, a escolha das cartas a serem publicadas na revista não é neutra e representa um gesto de interpretação dos editores da revista. Mais do que um gesto, um modo de administrar os sentidos para que eles não deslizem e produzam efeitos indesejáveis. Modo esse que é confirmado pela ressalva publicada na revista após as cartas "A revista "Brasil Cristão" não se responsabiliza pelo teor das cartas publicadas e se reserva o direito de adaptá-las sem alterar o conteúdo". Interessante observar que a revista não se responsabiliza pelo teor das cartas, mas pode adaptá-las e escolhe quais serão publicadas. Vale ainda ressaltar que nunca o conteúdo das cartas traz uma voz destoante da voz do editorial, tampouco um dizer que se contra-identifique com o dizer da Renovação Carismática Católica.

\section{CONSIDERAÇÕES FINAIS}

Enfim, a partir das análises das cartas e dos editoriais, pudemos observar como funcionam as vozes presentes no discurso da Renovação 
Carismática Católica, propagado por um veículo de mídia - a Revista Brasil Cristão. Vozes que marcam a heterogeneidade desse discurso, mas que apontam para uma única posição sujeito dominadora do padre e para um mesmo efeito de sentido: Jesus transforma-se em mercadoria e dono de empresa e o fiel em sócio-contribuinte, submisso à ordem divina. A voz do fiel é incluída nesse discurso apenas para evidenciar o sentido dominante, numa tentativa de mascarar o heterogêneo. O fiel é, então, uma espécie de telespectador passivo que aplaude e aprova o papel que lhe é delegado: contribuir com a obra do Senhor e atrair novos sócios. E tais efeitos de sentido são construídos graças a intervenção da mídia e a apropriação que o discurso religioso faz do discurso jornalístico. Assim, entre a voz de Deus e a voz do fiel, entre a forma empírica do discurso jornalístico e a forma material do discurso religioso, há um espaço de tensão que é preenchido pelo silêncio, mas também pelo dito, pelas relações simbólicas e imaginárias e pelo atravessamento da mídia, que se coloca a serviço da religião para evangelizar, para tornar o Brasil Cristão. E tal espaço só é possível de ser trabalhado graças ao olhar discursivo que lançamos sobre ele, considerando a intervenção do histórico, do social e do ideológico, que permite a análise da passagem do plano temporal ao divino, assim como a passagem da forma empírica à forma material. Desse modo, ocupei-me da opacidade desse objeto discursivo - o discurso religioso - analisando esse espaço de tensão que aí se inscreve.

\section{ANEXOS}

\section{ANEXO 1}

Não está aqui, mas ressuscitou...

Aleluia, Ele vive!

Esta maravilhosa e fantástica notícia dá novo sentido à nossa vida. Saber que podemos contar com o Amor de um Deus infinitamente poderoso deixa o nosso coração transbordando de alegria e paz!

Feliz Páscoa! É o que eu desejo a você, querido sócio de Jesus! Feliz vitória de Jesus sobre a sua mente, sobre o seu coração, sobre a sua vida, sobre a sua família. Feliz vitória de Jesus, que está Vivo, sobre todo o seu ser.

Agradeço, de coração, toda ajuda, a fidelidade, a generosidade e a solidariedade que você tem demonstrado pela Associação, que é do Senhor Jesus!

Espero que esta edição de "Brasil Cristão" ajude a fortalecer sua fé e sua confiança no Deus que vive para sempre! Meu abraço. (Assinatura 
do Padre Eduardo Dougherty). (BRASIL CRISTÃO, Editorial, abril/2000). PS.: Os grifos são da revista

\section{ANEXO 2}

Maria: Mãe há 2000 anos!

"Ave Maria cheia de graça, o Senhor é convosco. Bendita sois vós entre as mulheres e bendito é o fruto do vosso ventre, Jesus!"

Estas palavras devem estar constantemente em nossos lábios, pois elas nos aproximam daquela que melhor viveu a Vontade e os Projetos do Pai, trazendo-nos a salvação que é Jesus.

Maria é Mãe do Salvador e nossa mãe também, Maria é a Mãe por excelência. É a mulher cheia de graça e repleta do Espírito Santo.

O mês de maio é todo dedicado à Maria e às mães, por isso é um mês tão especial.

Neste mês vou rezar especialmente por todas as mães. Vou rezar também pela minha mãe, Mary, que tive a alegria de ver no mês passado.

Neste mês reze também por sua mãe. Reze especialmente através do "Cartão especial de Orações pelas Mães" (vivas ou falecidas) que estou enviando junto com esta revista. Vamos nos unir em orações pelas mães do mundo inteiro.

Sem dúvida é muito bom ter mãe. Porém, melhor ainda é saber que todos nós temos uma Santa Mãe no céu, que intercede dia e noite por todos e cada um em especial.

Temos muito a aprender com Maria: a abertura de coração ao Espírito Santo, o serviço ao próximo, o amor incondicional, a fidelidade em todos os momentos, a pureza, o silêncio, a perseverança no sofrimento, o espírito evangelizador.

Vamos pedir juntos que a Mãe de Jesus esteja conosco, todos os dias de nossas vidas, indicando-nos sempre o Caminho, a Verdade e a $V i d a$, a todos nós, pecadores, agora e na hora de nossa morte. Amém. (Assinatura do Pe. Eduardo Dougherty). (REVISTA BRASIL CRISTÃO, Editorial,maio/2000).

PS.: Os grifos são da revista.

\section{ANEXO 3}

Que a paz de Jesus e o Amor de Maria estejam com vocês!

Em dezembro/99 estava fazendo uma bateria de exames, pois foi constatado através de um ultra-som que eu estaria com um "nódulo suspeito". 
Nesta hora a fé da gente fica tão pequena que senti vergonha de mim mesma. Como não acreditar na palavra: "Pedi e recebereis"?

Rezava e pedia, pedia e rezava a Jesus e a Maria para que intercedessem por mim.

Por mais que o médico tentasse me consolar, era tudo em vão. Passei um mês de dezembro que só Deus sabe.....No começo deste ano estava marcado mais um exame que iria completar todos os que eu já havia feito. Chorava muito! Quando cheguei em casa e vi na caixa do correio a revista "Brasil Cristão", falei para mim mesma: "Nesta revista está a resposta para me consolar". Quando a tirei da embalagem, a única coisa que eu conseguia ler na capa era a palavra "Esperança". Foi outra crise de choro, mas, desta vez, um choro que me libertou e confortou. Graças a Deus não havia nada demais nos últimos exames, que foram mais minuciosos.

Esta revista é uma bênção para todos nós! Ela é simplesmente para a honra e glória de Deus e eu agradeço a Ele pela orientação que dá. Rezo sempre por vocês, que fazem a "Brasil Cristão" chegar até nós. Gostaria de dizer também que a revista de fevereiro está maravilhosa, clareando bastante a definição da Renovação Carismática.

Um abraço em Cristo para todos.

\section{Iara Teixeira Marques}

Mogi das Cruzes/SP

Pe. Eduardo, que Jesus o abençoe sempre: "Louvai ao Senhor porque Ele é bom".

A revista "Brasil Cristão" está cada vez mais bonita e boa.

A equipe está de parabéns e o senhor também, é claro. Por tudo louvamos a Deus! Gosto de ler a revista inteira, mas a matéria "A sós com Jesus" é uma verdadeira jóia.

A Ir. Cecília, o Pe. Dênis... não vou citar mais nomes, pois todos se expressam muito bem. Ser sócio desta obra de Deus é realmente um privilégio. À equipe força e luz. Deus os abençoe.

Ades David Silva Mortugaba/BA

(BRASIL CRISTÃO, abril/2000)

PS.: Os grifos são da revista.

\section{ANEXO 4}

Prezado Pe. Eduardo e todos amigos da Associação do Senhor Jesus, escrevo para mais uma vez parabenizá-los, porque através desta obra 
tenho recebido muitas graças do Senhor Jesus, quando há três anos me tornei sócio.

Bom Pe. Eduardo, eu era muito "amarrado" a outros canais de televisão, dos quais na maioria de seus programas só transmitem coisas malignas, era também ligado a músicas do mundo que também é um desastre para as nossas famílias.

Depois de ter me tornado sócio minha vida mudou completamente, principalmente quando assistindo ao programa "Louvemos o Senhor" o Campos Filho disse: "O Pe. Eduardo quer fazer com que as músicas católicas sejam as mais tocadas e ouvidas no mundo todo. Então deste dia em diante, só consigo ouvir músicas católicas, pois "quem canta reza duas vezes". E esta revista "Brasil Cristão" é realmente uma revista. Tudo nela é muito bom, e tem me ajudado muito em minha paróquia, na preparação de liturgia.

Fazemos encontros nas casas de muitos da Comunidade, sempre com o auxílio da revista que é uma bênção. Nas minhas orações sempre lembro da Associação e é com muita gratidão ao Senhor Jesus que com Seu Amor e Sua Misericórdia nos faz mais firmes na nossa Igreja Católica, posso dizer glórias e louvores a Ti Senhor.

Jair C.P. Azevedo Teixeira de Freitas/BA (REVISTA BRASIL CRISTÃO, maio/2000)

\section{BIBLIOGRAFIA}

COURTINE, Jean-Jacques. Analyse du discours politique. Paris, Larousse, Langages, n. 62, juin.1981.

DAVALLON, Jean. A imagem, uma arte de memória? In: ACHARD, Pierre et alii. Papel da memória. Trad. e intr.José Horta Nunes. Campinas, Pontes, 1999.

GRIGOLETTO, Evandra. Sob o rótulo do novo, a presença do velho: análise do funcionamento da repetição e das relações divino/temporal no discurso da Renovação Carismática Católica. Porto Alegre, PPGLetras/UFRGS, 2000. (Dissertação de Mestrado).

INDURSKY, Freda. A fala dos quartéis e as outras vozes. Campinas, Ed. da Unicamp, 1997.

MARIANI, Bethania. O PCB e a imprensa: os comunistas no imaginário dos jornais (1922-1989). Rio de Janeiro, Revan, Campinas, Ed. da Unicamp, 1998. 
ORLANDI, Eni. Terra à vista. Discurso do confronto: velho e novo mundo. São Paulo, Cortez, Campinas, Ed. da Unicamp, 1990.

_.. Interpretação: leitura e efeito do trabalho simbólico. Petrópolis, Vozes, 1996.

\section{Revistas}

BRASIL CRISTÃO. Ano 4, número 33, Campinas/SP, abril/2000.

BRASIL CRISTÃO. Ano 4, número 34, Campinas/SP, maio/2000. 